\title{
Experts e sua opinião sobre a Comunidade Surda: análise crítica de discursos de solidariedade em tempos de acessibilidade ${ }^{1}$
}

\author{
Juliana Barbosa Alves" \\ Cleide Emília Faye Pedrosa"
}

\section{Resumo}

Neste artigo, estudamos a comunidade surda, grupo vulnerável que sofre com a desigualdade social enquanto minoria linguística pelo olhar de profissionais que lidam com essa comunidade. Para tanto, nos fundamentamos na Análise Crítica do Discurso, cujo foco principal é analisar os discursos de problematizações sociais que atingem os vulneráveis. Isso posto, o objetivo é analisar os discursos de profissionais que trabalham com a comunidade surda contidos em comentários, no Facebook, sobre o tema da redação do Enem 2017. O diálogo teórico envolve os Estudos Surdos e a Análise Crítica do Discurso. Para atender às análises linguísticas, utilizamos as categorias da Gramática Sistêmico-Funcional, e, por se tratar de uma pesquisa de cunho social, empregamos a metodologia qualitativo-interpretativista. Como resultado, os discursos dos profissionais engajados com a causa surda nos levou a reflexões discursivas e sociais sobre a visão solidária que se deve ter dessa causa.

Palavras-chave: Análise Crítica do Discurso; Comunidade Surda; Desigualdade.

\section{Introdução}

A comunidade surda, como minoria linguística, vem sofrendo, há séculos, com a desigualdade social, marginalizada nas relações de poder pela comunidade majoritária, a ouvinte. Com o estigma de pessoas deficientes, enfrentando práticas de normatização, como o discurso hegemônico do oralismo ${ }^{3}$, o povo surdo lutou para ser reconhecido por sua diferença linguística, na medida em que o surdo "não é diferente unicamente porque não ouve, mas porque desenvolve potencialidades psicoculturais diferentes das dos ouvintes" (SÁ, 2002, p. 49). Diante desse

\footnotetext{
* Graduanda em Letras Libras na Universidade Federal de Sergipe, Bolsista de Iniciação Científica. E-mail: julialves01@hotmail.com

** Pós-doutoranda pela Universidade Federal de Sergipe Brasil/Universidade de Lisboa - Portugal (2019-2020), Docente do Departamento de Letras Libras (Língua Brasileira de Sinais) e do Programa de Pós-Graduação em Letras (PPGL) na Universidade Federal de Sergipe. E-mail: cleideemiliafayepedrosa@gmail.com
}

Data de submissão: dez. 2020 - Data de aceite: mar. 2021 http://dx.doi.org/10.5335/rdes.v17i01.11145 
cenário, buscamos aporte teórico na Análise Crítica do Discurso (ACD), pois, como assevera Jäger (2017, p. 128), a ACD "pode não apenas alertar contra usos eufemísticos e sensacionalistas da língua" e também "não apenas exercer uma crítica linguística, mas também uma crítica da sociedade". E, acima desses aspectos teóricos, ela pode, "em face das normas dominantes de democracia e justiça”, em seus resultados analíticos, "exigir uma tomada de posição, mesmo se isto for desconfortável e inadequado à paisagem 'política"' (JÄGER, 2017, p. 128).

Como a ACD se pronuncia com objetivo centralizado na denúncia de problemas sociais (FAIRCLOUGH, 2008; PEDROSA, 2008; RESENDE, 2017), então o objetivo deste artigo se coaduna com essa teoria/esse método, pois, com base na visão crítica das práticas sociais, nos propomos a analisar os discursos de profissionais que trabalham com a comunidade surda contidos em comentários no Facebook sobre o tema da redação do Enem 2017, a saber, "Desafios para a Formação do surdo no Brasil". Para tanto, cotejaremos tais comentários com a base teórica em pauta, na intenção de contribuir para a visão que se tem ou deveria ter da aprendizagem cidadã de grupos vulneráveis (PEDROSA, 2016), já que consideramos que a ACD mantém o foco dos seus estudos pelo viés dos grupos dominados, visando à igualdade social (LIRA; ALVES, 2018).
Para sustentação analítica, dialogamos com os Estudos Surdos, bem como com aspectos da história, da cultura e da identidade surdas (GESSER, 2012; QUADROS, 1997; SÁ, 2002). E, como a ACD é textualmente orientada, utilizamos, para atender às análises linguísticas, as categorias da Gramática Sistêmico-Funcional (GSF) (ALMEIDA, 2010; VIAN JR., 2010).

Seguimos o caminho da metodologia qualitativo-interpretativista (MAGALHÃES; MARTINS; RESENDE, 2017), tendo em vista que as pesquisas em ACD baseiam-se nessa metodologia. $\mathrm{O}$ corpus é formado a partir de comentários de profissionais, que lidam com a comunidade surda, acerca do tema da redação do Enem 2017 sobre a educação de surdos, em postagem no Facebook.

O presente texto terá o seguinte desenho: inicialmente, por esta introdução; em seguida, evidenciaremos o aporte teórico, a Análise Crítica do Discurso. Na sequência, abriremos o tópico de análise e de reflexão embasados na ACD e nos Estudos Surdos; por fim, apresentaremos alguns posicionamentos conclusivos.

\section{Análise Crítica do}

\section{Discurso: por uma leitura crítica de questões sociais de minorias}

A Análise Crítica do Discurso se iniciou como corrente linguística na década de 1990, dando um novo direcionamento 
aos estudos da linguagem, ao considerar o contexto do qual a prática linguageira emerge. Dessa forma, a ACD tem forte compromisso com o estudo das relações entre linguagem e poder nas práticas sociais (PEDROSA, 2008).

Essa perspectiva linguístico-social tem seu foco voltado para a linguagem, mais precisamente para o discurso, considerando-se o discurso como uso da linguagem (FAIRCLOUGH, 2008). Logo, a ACD busca, como objetivo principal, em suas análises, evidenciar problemas sociais de grupos vulneráveis que se encontram em relações de poder contidas nas práticas sociais para, com tal posicionamento teórico e político, desvelar tais opressões, pois, como nas palavras de Pereira (2017, p. 199-200), fazendo uma leitura de Iris Young, "todas as vítimas de opressão são, de algum modo, inibidas de desenvolver ou exercer as suas competências e de expressarem as suas necessidades, pensamentos e sentimentos. Com efeito, “[...] procurar a justiça, a igualdade e a democracia consiste em um ideal inescapável para a ciência crítica" (GONÇALVES-SEGUNDO, 2018, p. 79), mais especificamente para os analistas críticos do discurso.

Jäger (2017, p. 128) argumenta que “o pré-requisito teórico mais importante da $\mathrm{ADC}^{4}$ nos parece ser, contudo, o fato de ela insistir que ninguém detém o monopólio da verdade", em outras palavras, "que ninguém pode com isso requerer a legitimidade de seu poder e, assim, que ninguém está certo para sempre”. Com esse posicionamento se define, assim, "a condição básica para que acordos sensatos possam ser fechados e, além disso, para reconhecer que o poder não é apenas o poder de alguns poderosos".

Como se pode identificar, a ACD passa a ser um veículo de problematização, uma vez que coloca em discussão tanto o "reducionismo positivista" quanto "qualquer fundamentalismo". Dessa forma, via ACD, o campo da linguística se aparelha para confrontar problemas sociais (JÄGER, 2017).

Com esse posicionamento, cabe-nos, como linguistas, refletir sobre nossa capacidade de agir e resistir frente às relações de poder e de opressão vivenciadas por grupos vulneráveis, no caso em estudo, a comunidade surda, a fim de que visualizemos e vivenciemos uma sociedade não em que todos tenham direitos iguais, mas em que todos tenham direitos igualitários. Como explica Kymlicka (1996, p. 44, tradução nossa), "equidade, no processo de tomada de decisão, implica, entre outras coisas, ouvir e levar em consideração os interesses e as perspectivas da minoria"5.

Desse modo, tratar de direitos de grupos minoritários, ou vulneráveis, entre outros, tem a ver com tratar de seus direitos culturais. Consideramos, no caso, que esses direitos estão ligados aos direitos políticos, logo ligados à cidadania (TOU- 
RAINE, 2005). Dentre muitos temas questionados por minorias, não se pode negar que estão os direitos linguísticos e os direitos do currículo educativo. Nesses casos, encontrar respostas que sejam moralmente defensáveis e também politicamente viáveis tem se constituído um forte desafio que as democracias atuais têm enfrentado, conforme argumenta $o$ filósofo político Kymlicka (1996).

O filósofo enumera algumas das práticas de que os governos, ao longo da história, fizeram uso no que concerne às minorias culturais, sendo algumas dessas práticas nem sempre por ações meritórias (KYMLICKA, 1996). Exemplo disso é que algumas minorias foram eliminadas fisicamente e outras foram expulsas, não se eximindo, ainda, os casos de assimilação de forma coercitiva. Para a comunidade surda, registramos o caso de assimilação a partir das medidas do Congresso de Milão (1880), em que os surdos foram obrigados a serem ouvintes, ou seja, foi imposta a oralização (ROCHELLE, 1880). Ainda em tantos outros casos, as minorias foram tratadas como estrangeiros em sua própria terra, sendo privadas de seus direitos políticos.

Por outro lado, reconhecem-se as diversas iniciativas de proteger as minorias culturais e, desse modo, conseguir "regular conflitos potenciais entre culturas majoritárias e minoritárias"(KYMLICKA, 1996, p. 4, tradução nossa) ${ }^{6}$. Assim, com alguns passos sociais, os direitos das mi- norias têm recuperado ou alcançado algumas posições nas relações internacionais. A seguir, apontamos duas medidas: 1- A Organização para a Segurança e Cooperação na Europa (CSCE) - "adotou em 1991 uma Declaração sobre os Direitos das Minorias Nacionais e posteriormente estabeleceu um Alto Comissariado para as Minorias Nacionais em 1993 (KYMLICKA, 1996, p. 7) ${ }^{8}$; 2- Debate das Nações Unidas acerca de dois textos: direitos das pessoas pertencentes às minorías étnicas, religiosas, nacionais e lingüísticas, e um rascunho sobre uma Declaração Universal dos Direitos dos ìndigenas (KYMLICKA, 1996). Ainda, neste mesmo caminho, indicamos outras cartas e declarações: 1966 - Pacto Internacional sobre os Direitos Econômicos, Sociais e Culturais; 1992 - Carta Europeia das Línguas Regionais e Minoritárias; 1992 - Declaração da Organização das Nações Unidas Sobre os Direitos das Pessoas Pertencentes a Minorias Nacionais ou Étnicas, Religiosas e Linguísticas; 2005 - Comentário do Grupo de Trabalho sobre Minorias à Declaração da Organização das Nações Unidas Sobre os Direitos das Pessoas Pertencentes a Minorias Nacionais ou Étnicas, Religiosas e Linguísticas; 2005 - Convenção da UNESCO sobre a Proteção e Promoção da Diversidade das Expressões Culturais; 2007 - Fórum sobre Assuntos das Minorias pelo Conselho de Direitos Humanos (Resolução $6 / 15){ }^{9}$ 
Reconhecidamente, muitos países só aceitam as diferenças culturais consoante posicionamentos legais ou constitucionais, pois alguns deles se situam para além dos direitos comuns de cidadania, é o que Iris Young (apud KYMLICKA, 1996) denomina de "cidadania diferenciada". Como assinala Kymlicka (1996, p. 28 , tradução nossa) $)^{10}$ :

No entanto alguns direitos das minorias não criam desigualdades, mas sim as eliminam. Alguns grupos são prejudicados injustamente no mercado cultural, portanto, seu reconhecimento e apoio político remedia esse dano.

Se especificarmos a questão cultural para o povo surdo, saberemos o quanto os surdos têm sido não só excluídos, mas têm sofrido a força da estigmatização. No dizer de Sá (2002, p. 355, grifo do autor),

[...] seu universo cultural, suas estratégias de sobrevivência, seus valores e as características de seu comportamento têm sido preteridos, desvalorizados. Suas formas de agir, de pensar, de comunicar, de sentir, de dizer, têm sido negadas ao longo da história. Impôs-se a eles um modelo que jamais poderiam alcançar: o padrão de ter que ser o que não são. As expectativas absurdas, as escassas opções e os enormes limites impostos levaram a maioria deles a uma crise de identidade, a uma desvalorização pessoal e ao menosprezo pelo seu saber e pela sua cultura - manifestos mais intensamente na vida de tantos surdos que tentam esconder sua surdez.

Nesse sentido, a autora - com a qual concordamos - entende a cultura surda como sendo um campo de lutas em que se encontram inseridos díspares grupos sociais em torno do significado do que vem a ser a surdez e também os surdos nesta sociedade globalizada, acrescentando ainda o entendimento de identidade como "a fonte de significado e experiência de um povo" (CASTELLS, 2008, p. 22). Logo, podemos afirmar que as identidades do povo surdo "não se constroem no vazio, formam-se no encontro com os pares e a partir do conforto com novos ambientes discursivos" (SÁ, 2002, p. 101), sendo os ambientes discursivos aquilo que queremos abordar neste estudo.

\section{Metodologia: o caminho qualitativo- interpretativista da ACD}

Classificamos a pesquisa como qualitativo-interpretativista (MAGALHÃES; MARTINS; RESENDE, 2017) por se tratar de um estudo de cunho social. $\mathrm{O}$ viés qualitativo permite expressar "o tecido social da vida diária, o significado das experiências e o imaginário dos participantes da pesquisa" (MAGALHÃES; MARTINS; RESENDE, 2017, p. 30), enquanto o caráter interpretativista nos coloca em sintonia com o significado das ações sociais em que os sujeitos da pesquisa estão inseridos.

Como o ambiente discursivo dos discursos analisados é o Facebook, destacamos, em consonância com Teixeira, relido por Souza (2016), que o Facebook 
tem uma missão, qual seja, a de ser uma espécie de mapa de acordo com o qual as pessoas podem se mover no emaranhado dessa rede e fazer descobertas a partir desses encontros virtuais com outros atores sociais que lhes são próximos ou que lhes são recomendados. Em face disso, entendemos que o Facebook tem o poder de socializar várias pessoas, fato que nos levou a escolher essa mídia social como lócus para realizar a coleta do corpus.

O corpus corresponde a postagens de usuários que opinaram sobre o tema da redação do Enem 2017 ("Desafios para a Formação do surdo no Brasil”). Coletamos vinte e três postagens referentes a posicionamentos de surdos, familiares, candidatos ao Enem em que se concordava e/ou discordava da temática, entre outros. Dentre as postagens, selecionamos duas de profissionais que trabalham com surdos para serem analisadas.

O Enem, Exame Nacional do Ensino Médio, é realizado pelo INEP, Instituto Nacional de Estudos e Pesquisas Educacionais Anísio Teixeira, desde 1998. Essa prova é a forma de ingresso no ensino superior e nos programas de financiamento estudantil do governo. Após dois anos de início dessa forma de avaliação, começaram a ser aplicados alguns recursos de acessibilidade. Porém, apenas em 2017 o INEP lançou o recurso de acessibilidade "Videoprova em Libras"11 para surdos e deficientes auditivos. Daí ser coerente, em 2017, a exploração do tema da redação sobre a formação do surdo, dando visibilidade a essa causa. Atualmente, os recursos de acessibilidade para pessoas com surdez ou deficiência auditiva são tradutor intérprete de libras, videoprova em Libras, leitura labial e tempo adicional.

Para a análise discursiva e social dos textos, utilizaremos a ACD e os Estudos Surdos, já para a análise linguística faremos uso da Gramática Sistêmico-Funcional. Esta leva em consideração o contexto social em que se usa a linguagem, sendo, por isso, fundamental para as análises textualmente orientadas da ACD.

Três metafunções compõem a GSF: ideacional, interpessoal e textual. A ideacional nos orienta a identificar que visão do mundo é assumida pelo autor do texto; a interpessoal demonstra que relações interacionais constroem o texto, e a textual diz respeito à estrutura do texto, como ele foi construído.

Como recorte analítico, selecionamos a metafunção interpessoal, que "desvela os papéis e as relações que os interlocutores constroem no ato das trocas interativas" (BERNARDINO, 2015, p. 566). Em seu Sistema da Avaliatividade, a metafunção interpessoal organiza em categorias os recursos léxico-gramaticais empregados nas avaliações (VIAN JR., 2010).

Os diferentes recursos utilizados para avaliação da linguagem permitem ao autor atribuir valor à sua experiência social. Como defende Oliveira (2014, p. 248), 
[...] muito mais do que servir como recurso de expressão de opinião, [a avaliação] é um instrumento de construção e negociação de valores socialmente compartilhados".

O Sistema de Avaliatividade é subdividido em subsistemas, a saber: Atitude, Gradação e Engajamento. Dentre estes, o subsistema de Atitude atende ao objetivo da análise. Compondo as categorias de tal subsistema, encontramos: Afeto, na qual o sujeito expressa emoção na sua avaliação, expondo sentimentos; Julgamento, em que o sujeito julga o caráter e a atitude das pessoas; e Apreciação, na qual o sujeito atribui valores às coisas, de forma positiva ou negativa (VIAN JR., 2010).

\section{Estudos Surdos: Análise crítica da visão de profissionais acerca da comunidade surda}

Reforçamos que a Análise Crítica do Discurso tem seu objetivo centrado em estudar problemas sociais (PEDROSA, 2008; RESENDE, 2017), por isso entendemos o valor desse campo teórico e analítico para o enfrentamento das questões relacionadas ao sujeito surdo, como minoria linguística, em busca de seus direitos como cidadão, além da preocupação de profissionais que estão inseridos nesse contexto. E adicionamos, em consonância com Gonçalves-Segundo (2018) e Melo (2018), que a ACD não só estuda os problemas sociais, mas também denuncia relações de poder e de opressão, engajando-se em conscientizar aqueles que se encontram em situações de opressão, visando a seus empoderamentos.

O povo surdo, como minoria linguística, tem uma experiência comum de vida, e isso se manifesta em sua cultura, incluindo crenças, atitudes, histórias, normas, valores, tradições literárias, arte, e, não resta dúvida, sua identidade se fortalece quando eles, os surdos, se relacionam com seus pares (SÁ, 2002). Diante disso, fazemos um questionamento para reflexão: como lidar com um aluno que, devido a relações de opressão, não é empoderado quanto à sua língua, à sua identidade e à sua cultura? Podemos verificar, na sequência discursiva a seguir, a visão de um profissional (intérprete) que vivenciou essa experiência:

SD112: "Olá, hoje foi um dia marcante para os surdos, para a Libras e para mim também como profissional da área. Exatamente ao meio dia recebi dezenas de mensagens no meu instagram de pessoas que me acompanham avisando que a redação do enem deste ano falava sobre "os desafios da formação educacional de surdos no Brasil". Fiquei surpreso e ao mesmo tempo feliz (Só espero que não saiam muitas pérolas do enem nessa redação rsrs). Eu fiquei feliz porque enfrentei de perto muitos desafios na minha época de intérprete e por consequência tenho muitas ideias e realidades para falar. $\mathrm{E}$ só pra constar esse tema não tem nada de difícil, a única coisa que ele é, é não ser visto". 
O sujeito se instaura discursivamente, sendo solidário com a causa surda e destacando a importância do tema da redação do Enem para os surdos e para a Língua Brasileira de Sinais (Libras), como também para ele enquanto membro atuante da comunidade surda. Aclarando, assinalamos que podem ser considerados como membros da comunidade surda surdos, familiares, professores surdos, professores bilíngues e intérpretes (STROBEL, 2007, 2009), ou seja, todos os membros que desenvolvem uma relação de "caráter de relações solidárias", pois os membros dessa comunidade se estimam entre si. E solidariedade, para Honneth (2009, p. 209), é compreendida, "numa primeira aproximação, [como] uma espécie de relação interativa em que os sujeitos tomam interesse reciprocamente por seus modos distintos de vida". Nesse contexto, concordamos com Young (2006, p. 158-159) quando trata do seu conceito de interesse:

[...] defino "interesse" como aquilo que afeta ou é importante para os horizontes de vida dos indivíduos ou para as metas das organizações. Um agente individual ou coletivo tem interesse naquilo que é necessário ou desejável para que sejam alcançados os $\square$ ns que ele almeja. Isso inclui tanto os recursos materiais quanto a habilitação para exercer capacidades, por exemplo, de expressão cultural, de in $\square$ uência política, de interferência nas decisões econômicas.

Assim, a comunidade surda envolve todas as pessoas que se identificam com o povo surdo, bem como trabalham com ele e o defendem, incluindo eles mesmos. Relacionado a esse conceito, entende-se como povo surdo os sujeitos que constroem sua visão de mundo e suas experiências através da percepção visual e pertencem a um grupo de sujeitos que compartilham a mesma história, as tradições, os costumes e a cultura (STROBEL, 2009).

No fragmento "fiquei surpreso e ao mesmo tempo feliz" (grifo nosso), notamos que ele se sente feliz por ver a comunidade surda ser reconhecida, por ter vivenciado muitas lutas e muitos desafios enquanto intérprete. A lexia destacada traz uma carga emocional (subsistema Afeto) diante do acontecimento.

Desde 1992 a Feneis, Federação Nacional de Educação e Integração dos Surdos, em um encontro nacional de intérpretes, lançou o Código de Ética que rege a função, porém apenas com a Lei $\mathrm{n}^{\circ}$ 10.436, de 2002 (BRASIL, 2002), a qual reconhece a Libras como língua do povo surdo, o profissional intérprete passou para um outro nível na história da comunidade surda (QUADROS, 2004; SANDER, 2009).

No entanto, somente em 2010 a profissão de intérprete de Libras foi regulamentada, através da Lei no 12.319 , de 2010 (BRASIL, 2010). Com relação às atribuições do tradutor e intérprete, a lei traz, em seu Art. 6, que ele deve: "II - interpretar, em Língua Brasileira de Sinais - Língua Portuguesa, as ati- 
vidades didático-pedagógicas e culturais desenvolvidas nas instituições de ensino nos níveis fundamental, médio e superior, de forma a viabilizar o acesso aos conteúdos curriculares" (BRASIL, 2010). Porém, nem isso garante $o$ atendimento desse profissional em todas as situações que a interpelação do surdo com o ouvinte necessita.

Ainda no que diz respeito à lexia em destaque ("surpreso"), podemos identificar que ele faz uso de um julgamento e/ ou uma apreciação, um julgamento das pessoas não solidárias à causa surda, já que há vozes identificadas inferencialmente, que julgavam o tema difícil ["o tema é difícil”], e a voz do sujeito discursivo, a qual contradiz essas vozes antagônicas ("E só pra constar esse tema não tem nada de difícil"). Quanto à leitura da Apreciação, interpretamos que se refere, negativamente, às instituições políticas e pedagógicas que tratam a causa surda com descaso ("...a única coisa que ele é, é não ser visto"). Citamos aqui um caso recente de desatenção para com a causa surda: trata-se do Decreto no $10.185^{13}$, de 20 de dezembro de 2019, do Governo Federal, que "extingue cargos efetivos vagos e que vierem a vagar dos quadros de pessoal da administração pública federal e veda a abertura de concurso público e o provimento de vagas adicionais para os cargos especificados", sendo que nesse meio se encontra o cargo de tradutor intérprete de Libras. Com isso, temos um retrocesso diante de todas as conquistas da comunidade surda.

Nossa leitura crítica recai sobre o fato de que foram necessárias quase duas décadas para que o INEP atendesse a uma Tecnologia Assistiva mais efetiva para seus cidadãos surdos, a exemplo da Videoprova do Enem em Libras, mesmo que já desde 2002 (Lei da Libras: Lei $\mathrm{n}^{\mathrm{0}}$ 10.436, de 24 de abril de 2002) tenhamos o reconhecimento da Libras como língua do povo surdo, dando-se, em 2005, sua regulamentação (BRASIL, 2005). Evidencia-se mais uma vez um grande fosso social em relação à educação dos surdos.

No entanto, a leitura crítica séria também procura analisar os dois lados: os avanços e os retrocessos. Mesmo a comunidade surda tendo sido negligenciada por muito tempo, não podemos deixar de reconhecer as conquistas que ocorreram nas últimas décadas, no Brasil, principalmente com o reconhecimento da Língua Brasileira de Sinais, Libras, conforme a Lei ${ }^{\circ}$ 10.436/2002 (BRASIL, 2002), regulamentada pelo Decreto $\mathrm{n}^{\circ}$ 5.626/2005 (BRASIL, 2005), como meio legal de comunicação da comunidade surda, representando o reconhecimento dos seus direitos e dando outro status à Cultura Surda.

O reconhecimento da Libras, em 2002, foi uma vitória para a comunidade surda que vivenciou por muitos anos sua cultura e sua identidade serem invisíveis (“...a única coisa que ele é, é não ser vis- 
to.”). Contudo, fazemos uma crítica ao descompasso existente até a profissão de tradutor e intérprete de Libras ser reconhecida, regulamentada pela Lei $\mathrm{n}^{\circ}$ 12.319/2010 (BRASIL, 2010), tendo em vista que o Decreto no 5.626 (BRASIL, 2005), de 22 de dezembro de 2005, já garantia a presença do tradutor e intérprete em sala de aula. Em seu Art. 21, determinava que um ano após a publicação do Decreto, em 2006, as instituições federais de educação, básica e superior, "devem incluir, em seus quadros, em todos os níveis, etapas e modalidades, o tradutor e intérprete de Libras - Língua Portuguesa, para viabilizar o acesso à comunicação, à informação e à educação de alunos surdos" (BRASIL, 2005, s/p).

Em consonância com as legislações vigentes, para inclusão do surdo na educação, foi criado, na Universidade Federal de Santa Catarina (UFSC), o primeiro curso de Graduação em Letras Libras Bacharelado, na modalidade a distância, para formação de tradutores e intérpretes de Libras-Português. Dessa forma, a UFSC se tornou referência na formação de profissionais nessa área, formando mais de $1.000^{14}$ intérpretes em parceria com diversas instituições de todo o Brasil. Essa iniciativa atendeu ao Decreto $\mathrm{n}^{\mathrm{o}} 5.626$, de 2005 (BRASIL, 2005), que estipulou um prazo de dez anos para a formação do tradutor e intérprete de Libras-Língua Portuguesa por meio de curso superior (Art. 17).
A função de traduzir/interpretar é singular, dado que a atuação desse profissional leva-o a interagir com outros sujeitos, a manter relações interpessoais e profissionais, que envolvem pessoas com surdez e ouvintes, sem que esteja efetivamente implicado nelas, pois sua função é unicamente a de mediador da comunicação. O tradutor e intérprete, ao mediar a comunicação entre usuários e não usuários da Libras, deve observar preceitos éticos no desempenho de suas funções, entendendo que não poderá interferir na relação estabelecida entre a pessoa com surdez e a outra parte, a menos que seja solicitado. [...] Entende-se como postura ética uma atitude solidária, pela qual esses profissionais lutam pelo respeito às pessoas com surdez, assim como por qualquer outra pessoa. Existem várias áreas de atuação do tradutor e intérprete de Libras e Língua Portuguesa que merecem ser objeto de reflexão de todos os que atuam com pessoas com surdez usuárias da Libras (DAMÁZIO, 2007, p. 49-50).

Podemos imaginar os desafios enfrentados por esses profissionais que, antes do reconhecimento de sua profissão, atuavam praticamente de forma "solidária", sendo sensíveis à causa do outro. Na maioria dos casos, o encontro com a língua de sinais se dá através de contato familiar ou convivência social. Em seu interesse afetivo para com a causa surda, esses profissionais se engajaram em prol da igualdade de direitos para toda a comunidade surda, e tal fato pode ser constatado ao fazermos uma análise crítica, tendo em vista que, em seu engajamento político, a ACD tem como principal objetivo estudar as práticas sociais pelo viés dos grupos dominados, visando à igualdade social (LIRA; ALVES, 2018). 
Na sequência discursiva abaixo, podemos observar o relato de um professor de surdos sobre a realidade enfrentada por esses profissionais.

SD2: "Imagino o que devem estar pensando os pseudoeducadores que já tive o desprazer de cruzar na minha vida laboral sobre o tema do ENEM. E aos que sempre encararam com dialogicidade, comprometimento e amor, se sintam representados, pois sei que saberiam tirar de letra uma discussão sobre esse tema, pois quem viveu o desafio de educador em meio ao preconceito contra o surdo, sabe que um dos grandes desafios é a falta de humanidade que paira sobre alguns espaços educacionais. Gostaria muito de ver a cara desses pseudoeducadores dizendo que discentes não iriam conseguir sucesso pq são surdos numa discussão sobre a redação da Enem".

O sujeito SD2 se insere discursivamente já assumindo uma avaliação por julgamento. No contexto da GSF, "o julgamento tem a ver com questões de 'ética', uma análise normativa do comportamento humano baseado em regras ou convenções de comportamento" (ALMEIDA, 2010, p. 106) No trecho "pseudoeducadores", utilizado duas vezes no fragmento, identificamos a crítica a profissionais alheios à causa surda, e, no trecho "comprometimento e amor", em discurso opositivo, faz-se uma avaliação positiva de outros educadores solidários à causa. Desse modo, o texto constrói uma arena em que os interlocutores se encontram em campos discursivos divergentes. Ao lado dos "pseudoeducadores", juntam-se outras lexias e expressões negativas, tais como: "preconceito contra o surdo"; "discentes não iriam conseguir sucesso". Do outro lado, o daqueles que têm "comprometimento e amor", juntam-se as construções positivas do texto: "saberiam tirar de letra uma discussão sobre esse tema", "pois quem viveu o desafio de educador [...] sabe que um dos grandes desafios é a falta de humanidade que paira sobre alguns espaços educacionais”. Assim, com essa arena discursiva, visualizamos a arena das práticas sociais que ainda sustentam a exclusão e o preconceito contra o diferente.

Esse discurso de SD2 nos conduz a refletir sobre posicionamentos políticos e estratégias pedagógicas que, de fato, proporcionem a efetiva inclusão escolar do aluno com surdez. O professor deve buscar recursos diversos para a prática em sala de aula, recursos esses que estimulem vivências para o aluno surdo, fazendo com que a aprendizagem dele seja eficaz, uma vez que está assegurado por lei o atendimento educacional especializado (AEE), sendo garantida uma educação bilíngue para alunos com surdez em todo o processo educativo (DAMÁZIO, 2007). Nesse sistema, destacam-se três momentos didático-pedagógicos, os quais foram formatados por nós desta maneira: 
$1^{\circ}$ - Momento do Atendimento Educacional Especializado em Libras na escola comum, em que todos os conhecimentos dos diferentes conteúdos curriculares são explicados nessa língua por um professor [...];

$2^{\text {o }}$ - Momento do Atendimento Educacional Especializado para o ensino de Libras na escola comum, no qual os alunos com surdez terão aulas de Libras [...];

$3^{\text {o }}$ - Momento do Atendimento Educacional Especializado para o ensino da Língua Portuguesa, no qual são trabalhadas as especificidades dessa língua para pessoas com surdez (DAMÁZIO, 2007, p. 25).

Tendo em vista as dificuldades enfrentadas pelos surdos em sua história educacional, é justificável o julgamento negativo feito a todos os professores que trataram os alunos surdos com descaso, como expõe o sujeito discursivo: "o desafio de educador em meio ao preconceito contra o surdo". Em seu percurso escolar, os surdos se deparam com muitos desafios. Inicialmente, era usada a proposta oralista, que se baseava na normatização da pessoa surda, enfatizando a língua oral, considerada como uma imposição da maioria linguística. Em seguida, o bimodalismo passa a ser utilizado, que é o uso simultâneo de sinais e da fala oral. Esse sistema foi considerado, também, ineficiente, pois desconsidera a cultura surda e a riqueza da língua de sinais. Porquanto, como defendem Perlin e Strobel (2014, p. 26),

[...] para o sujeito surdo ter acesso a informações e conhecimentos e para estabelecer sua identidade é essencial criar uma ligação com o povo surdo o qual usa a sua língua em comum: a língua de sinais
$\mathrm{E}$ as autoras ainda reforçam que a língua de sinais "é uma das principais marcas da identidade de um povo surdo por ser uma das peculiaridades da cultura surda”.

Essa perspectiva se coaduna à proposta hoje aceita e difundida, o bilinguismo, em que há a língua de sinais, considerada como natural e como a primeira língua dos surdos, e a língua vernácula do seu país, isto é, uma segunda língua que será ensinada através de sua língua natural (QUADROS, 1997, 2010; NEVES, 2017). Esse contexto “implica reconhecimento do status da língua nos níveis linguístico, cultural, social e político" (QUADROS, 2010, p. 33).

Um grupo de trabalho do Ministério da Educação, formado por especialistas na área da surdez, desenvolveu, em 2014, um relatório sobre a Política Linguística de Educação Bilíngue - Língua Brasileira de Sinais e Língua Portuguesa. No documento, a educação bilíngue

[...] é entendida, como a escolarização que respeita a condição da pessoa surda e sua experiência visual como constituidora de cultura singular, sem, contudo, desconsiderar a necessária aprendizagem escolar do português (BRASIL, 2014, p. 6).

Nesse sentido, no relatório, a escola bilíngue para surdos é apresentada como "específicas e diferenciadas", e, para a seleção, se leva em consideração "a especificidade linguístico cultural reconhecida e valorizada pela Convenção 
sobre Direitos das Pessoas com Deficiência", com objetivo "da promoção $d a$ identidade linguística da comunidade surda, bem como do favorecimento do seu desenvolvimento social" (BRASIL, 2014, p. 6, grifo do autor).

Verificamos também que o discurso de SD2 traz uma carga emocional forte (subsistema Afeto), nos levando a inferir que já foi, ou é, professor de surdos, aspecto observado nos trechos "pois quem viveu o desafio de educador em meio ao preconceito contra o surdo" e "tive o desprazer de cruzar na minha vida laboral sobre o tema do Enem" ("Desafios para a Formação do surdo no Brasil”). Dentre as lexias, no comentário, que ressaltam os enfrentamentos da história da educação do surdo, podemos apontar "desafio" e "preconceito", coadunando-se ao que explica Sá (2002, p. 71): "a história dos surdos começa muda, apagada e triste”, e esse começo é recorrente nos "segmentos minoritários", como destaca ainda a autora. Com efeito, a sociedade precisa mudar seu posicionamento político no enfrentamento das questões dos grupos minoritários e na valorização de sua cultura, respeitando seus direitos e sua busca por sua cidadania (TOURAINE, 2005).

Em relação aos surdos, os direitos que mais se destacam são o direito linguístico e a um currículo educativo adequado, mas encontrar essas respostas, nas democracias, tem sido um forte desafio
(KYMLICKA, 1996). No Art. 27 do Pacto Internacional sobre os Direitos Civis e Políticos de 1966, está prescrito que nos Estados em que existam pessoas de minorias linguísticas (entre outros tipos de minorias), estas não deveriam ser privadas, juntamente com os outros membros de seu próprio grupo, do direito de ter a sua própria vida cultural, e também a sua própria língua.

Nesse contexto, o discurso do sujeito surdo como deficiente e imperfeito, incapaz de participar da vida "normal" da sociedade, é muitas vezes naturalizado, tido como legítimo, aceito sem questionamentos. Dessa forma, grupos hegemônicos mantêm seus privilégios, sustentando as desigualdades (GONÇALVES-SEGUNDO, 2018). Por isso a importância de se trazer ao debate questões da causa surda, como um tema de redação do Enem, na medida em que isso leva sujeitos solidários à causa surda a se manifestarem, trazendo visibilidade a esse grupo vulnerável. Completamos esse pensamento com o que expõe Van Dijk (2008, p. 114, grifo nosso):

[...] a reflexão acerca do papel dos acadêmicos na sociedade e na polis transforma-se em uma parte inerente da tarefa proposta pela análise do discurso. Isso talvez signifique, entre outras coisas, que os analistas do discurso orientam suas pesquisas em solidariedade e cooperação com os grupos dominados.

Entendemos que os professores, dentro do seu papel, precisam se mos- 
trar solidários para com a causa surda, interessando-se por essa peculiaridade do seu aluno, para que assim a passagem deste pela vida escolar vá além da aprendizagem de conteúdos, sendo uma aprendizagem para a vida, ajudando esse aluno a se reconhecer efetivamente em sua identidade e sua cultura diante da sociedade, pois não podemos conceber que um cidadão não tenha direito à acessibilidade em qualquer aspecto da vida social.

\section{Reflexões (ditas) finais}

Diante do objetivo que propomos, analisar os discursos de profissionais que trabalham com a comunidade surda, podemos observar que o posicionamento desses profissionais (intérprete e professor) foi de caráter solidário à causa surda.

Relações dessa espécie podem se chamar "solidárias" porque elas não despertam somente a tolerância para com a particularidade individual da outra pessoa, mas também o interesse afetivo por essa particularidade: só na medida em que eu cuido ativamente de que suas propriedades, estranhas a mim, possam se desdobrar, os objetivos que nos são comuns passam a ser realizáveis (HONNETH, 2009, p. 210-211).

Dessa forma, diante das análises linguísticas aqui empreendidas, utilizando-se a Gramática Sistêmico-Funcional, mais especificamente o sistema de avaliatividade, o uso de certos recursos léxico-gramaticais ("comprometimento", "amor", "marcante", "surpreso", "feliz" e "desafios") nos fez perceber que os sujeitos discursivos foram à sua rede social, o Facebook, expressar, com suas postagens, apoio à luta da comunidade surda por direitos iguais e que esses profissionais, de fato, se sentem, e são, integrantes da comunidade surda.

Diante do exposto, consideramos que reconhecer o surdo como minoria linguística é imprescindível para se pensar em uma educação efetiva, na qual são levadas em consideração sua língua, sua identidade e sua cultura. Com isso, seguimos a orientação de que "a educação bilíngue deve ser instaurada tomando como ponto de partida agrupamentos de surdos em um ambiente bilíngue com pessoas surdas e ouvintes que usam a língua de sinais" (QUADROS, 2019, p. 149).

Os professores e intérpretes são parte essencial nessa construção, como constatamos nos excertos apresentados. Vimos como esses profissionais desconstroem discursos hegemônicos ("preconceito contra o surdo", "fiquei surpreso", "enfrentei de perto muitos desafios", "esse tema não tem nada de difícil"), buscando desvelar tais discursos em prol do empoderamento dos surdos, questão cara à ACD. Assim, através da tomada de consciência dos seus direitos, concebemos que "se torna possível aos surdos imaginarem outras representações para narrarem 
a própria história do que significa ser surdo" (SKLIAR, 2016, p. 30).

Por fim, buscamos, com este trabalho, dar visibilidade à comunidade surda. Com efeito, pretendemos influenciar novas reflexões em outros trabalhos, pois acreditamos que o tema, infelizmente, ainda está assentando como assunto a ser debatido e defendido, e, ademais, almejamos possibilitar reflexões sobre e com a comunidade surda na busca por conscientização e empoderamento de sua cultura e sua identidade.

\section{Experts and their opinion} about Deaf Community: critical analysis of solidarity speeches in times of accessibility

\section{Abstract}

In this article, we studied the deaf community, a vulnerable group that suffers from social inequality as a linguistic minority, through the eyes of professionals who deal with this community. For that, we are based on Critical Discourse Analysis, whose main focus is to analyze the speeches of social problematizations that affect vulnerable people. That said, the objective is to analyze the speeches of professionals who work with the deaf community, contained in comments on Facebook, on the theme ENEM 2017 compositions. The theoretical dialogue involves Deaf Studies and Critical Discourse Analysis. To assist linguistic analysis, we used the categories of Systemic Functional Grammar. As it is social research, we used the quali- tative-interpretative methodology. As a result, the speeches of the professionals engaged with the deaf cause led us to discursive and social reflections on the solidarity view that one must have about it.

Keywords: Critical Discourse Analysis; Deaf Community; Inequality.

\section{Referências}

ALMEIDA, F. S. D. P. Atitude: afeto, julgamento e apreciação. In: VIAN JR., O.; SOUZA, A. A. de; ALMEIDA, F. A. S. D. P. (Orgs.). A linguagem da avaliação em língua portuguesa. Estudos sistêmico-funcionais com base no Sistema de Avaliatividade. São Carlos: Pedro \& João Editores, 2010. p. 99-112.

BERNARDINO, C. G. A metafunção interpessoal: um olhar sobre o artigo acadêmico de linguística. Rev. bras. linguist. apl., Belo Horizonte, vol.15, n. 3, p. 565592, jul./set., 2015. Disponível em: <https://www.scielo.br/scielo.php?pid=S1984$-63982015000300565 \& \mathrm{script}=\mathrm{sci}$ abstract\&tlng=pt $>$. Acesso em: 31 mar. 2020.

BRASIL. Lei $n^{\circ}$ 10.436, de 24 de abril de 2002. Dispõe sobre a Língua Brasileira de Sinais - Libras e dá outras providências. Brasília, 2002. Disponível em: <http://www. planalto.gov.br/ccivil_03/leis/2002/L10436. htm >. Acesso em: 06 jan. 2019.

BRASIL. Decreto $n^{\circ} 5.626$, de 22 de dezembro de 2005. Regulamenta a Lei no 10.436 , de 24 de abril de 2002, que dispõe sobre a Língua Brasileira de Sinais - Libras, e o art. 18 da Lei no 10.098 , de 19 de dezembro de 2000. Brasília, 2005. Disponível em: <http:// www.planalto.gov.br/ccivil_03/_ato20042006/2005/decreto/d5626.htm>. Acesso em: 06 jan. 2019.

BRASIL. Lei $n^{-} 12.319$, de 01 de setembro de 2010. Regulamenta a profissão de Tra- 
dutor e Intérprete da Língua Brasileira de Sinais - LIBRAS. Brasília, 2010. Disponível em: <http://www.planalto.gov.br/ccivil_03/_ ato2007-2010/2010/lei/l12319.htm>. Acesso em: 06 jan. 2019.

BRASIL. Lei $n^{\circ}$ 13.146, de 06 de julho de 2015. Institui a Lei Brasileira de Inclusão da Pessoa com Deficiência (Estatuto da Pessoa com Deficiência). Brasília, 2015. Disponível em: <http://www.planalto.gov.br/ccivil_03/_ ato2015-2018/2015/lei/l13146.htm>. Acesso em: 06 jan. 2019 .

BRASIL. Relatório sobre a Política Linguística de Educação Bilíngue - Língua Brasileira de Sinais e Língua Portuguesa. Grupo de Trabalho, designado pelas Portarias n. 1.060/2013 e n. 91/2013 do MEC/SECADI. Brasília: MEC/SECADI, 2014.

CASTELLS, M. O poder da identidade. A era da informação: economia, sociedade e cultura. v. 2, 6. ed. Tradução: Klauss Brandini Gerhardt. São Paulo: Paz e Terra, 2008.

DAMÁZIO, M. F. M. Formação Continuada a Distância de Professores para o Atendimento Educacional Especializado: Pessoa com Surdez. Brasília: SEESP, SEED, MEC, 2007.

FAIRCLOUGH, N. Discurso e mudança social. Tradução de Izabel Magalhães. Brasília: Editora Universidade de Brasília, 2008.

GESSER, A. O ouvinte e a surdez: sobre ensinar e aprender a libras. São Paulo: Parábola Editorial, 2012.

GONÇALVES-SEGUNDO, P. R. Discurso e prática social. In: BATISTA JR., J. R. L.; SATO, D. T. B.; MELO, I. F. de. (Orgs.). Análise de discurso crítica para linguistas e não linguistas. São Paulo: Parábola, 2018. p. 78-103.

HONNETH, A. Luta por reconhecimento: a gramática moral dos conflitos sociais. São Paulo: Editora 34, 2009.

JÄGER, M. Quão crítica é a análise de discurso crítica? In: RESENDE, V. de M.; REGIS, J. F. da S. (Orgs.). Outras perspectivas em análise de discurso crítica. Campinas, SP: Pontes Editores, 2017. p. 103-130.

KYMLICKA, W. Ciudadanía multicultural: Una teoría liberal de los derechos de las minorias. Barcelona: Editorial Paidós, 1996.

LIRA, L. C. E.; ALVES, R. B. C. Teoria social do discurso e evolução da análise de discurso crítica. In: BATISTA JR, J. R. L.; SATO, D. T. B.; MELO, I. F de. (Orgs). Análise de discurso crítica para linguistas e não linguistas. São Paulo: Parábola, 2018. p. 104-122.

MAGALHÃES, I.; MARTINS, A. R.; RESENDE, V. de M. Análise de discurso crítica: um método de pesquisa qualitativa. Brasília: Editora UnB, 2017.

MELO, I. F. de. História da análise de discurso crítica. In: BATISTA JR., J. R. L.; SATO, D. T. B.; MELO, I. F. de. (Orgs.). Análise de discurso crítica para linguistas e não linguistas. São Paulo: Parábola, 2018. p. 20-35.

NEVES, B. C. Educação bilíngue para surdos e as implicações para o aprendizado da Língua Portuguesa como segunda língua. 2017. Tese (Doutorado em Linguística) Programa de Pós-Graduação em Linguística, Universidade Federal de Santa Catarina, Florianópolis, 2017.

OLIVEIRA, D. M. de. O SISTEMA DE AVALIATIVIDADE: Aspectos teóricos e práticos. $G E P I A D D E$. Itabaiana, ano 08 , vol. 15 , p. 245-264, jan./jun., 2014.

PEDROSA, C. E. F. Análise crítica do discurso: do linguístico ao social no gênero midiático (interface: letras e comunicação social). São Cristóvão: Editora UFS; Aracaju: Fundação Oviêdo Teixeira, 2008.

PEDROSA, C. E. F. Análise crítica do discurso e a proposta da corrente nacional: da abordagem às primeiras pesquisas. In: KALLARRARI, C.; BESSA, D.; PEREIRA, A. S. (Orgs.). Estudos linguísticos e formação docente. São Paulo: Pontes, 2016. p. 69-100.

PEREIRA, A. C. Justiça e inclusão: desafios contemporâneos aos movimentos feministas, 
na perspectiva de Iris Young. Dissonância, Campinas, vol. 1, n. 2, p. 195-208, dez., 2017.

PERLIN, G.; STROBEL, K. História cultural dos surdos: desafio contemporâneo. Educar em Revista, Curitiba, n. 2, p. 17-31, Edição Especial, 2014.

QUADROS, R. M. de. Educação de surdos: aquisição da linguagem. Porto Alegre: Artmed, 1997.

QUADROS, R. M. de. O tradutor e intérprete de língua brasileira de sinais e língua portuguesa. Secretaria de Educação Especial; Programa Nacional de Apoio à Educação de Surdos. Brasília: MEC; SEESP, 2004.

QUADROS, R. M. de. O 'Bi' em bilinguismo na educação de surdos. In: FERNANDES, E. Surdez e bilinguismo. 4. ed. Porto Alegre: Mediação, 2010. p. 27-37.

QUADROS, R. M. de. Libras. São Paulo: Parábola, 2019.

RESENDE, V. de M. Análise de discurso crítica: reflexões teóricas e epistemológicas quase excessivas de uma analista obstinada. In: RESENDE, V. de M.; REGIS, J. F. da S. (Orgs.). Outras perspectivas em análise de discurso crítica. Campinas, SP: Pontes Editores, 2017. p. 11-51.

ROCHELLE, E. L. Le Congrés de Milan pour l'amélioration du sort des sourds- muets; rapport adresse a M. Eugène Pereire. Paris: M. Saint-Jorre, 1880.

SÁ, N. R. L. de. Cultura, poder e educação de surdos. Manaus: Editora da Universidade Federal do Amazonas, 2002.

SANDER, R. Questões do intérprete da língua de sinais na universidade. In: LODI, A. C. B.; et al. (Orgs.). Letramento e minorias. 3. ed. Porto Alegre: Mediação, 2009. p. 129-135.

SKLIAR, Carlos. Os estudos surdos em educação: problematizando a normalidade. In: SKLIAR, Carlos (Org). A surdez: um olhar sobre as diferenças. 3. ed. Porto Alegre: Mediação, 2016. p. 7-32.
SOUZA, M. C. de. A "Luta por reconhecimento" no Facebook: a comunicação social nas redes sociais, uma interpretação sociológica. 2016. Dissertação (Mestrado em Sociologia) - Programa de Pós-Graduação em Sociologia, Universidade Federal de Sergipe, São Cristóvão, 2016.

STROBEL, K. L. História dos surdos: representações mascaradas das identidades surdas. In: QUADROS, R. M. de; PERLIN, G. (Orgs). Estudos Surdos II. Petrópolis, RJ: Arara Azul, 2007. p. 18-37.

STROBEL, K. L. História da educação de surdos. Material de estudos da disciplina História da Educação dos Surdos. Universidade Federal de Santa Catarina, 2009.

TOURAINE, A. Um novo paradigma para entender o mundo de hoje. Lisboa, Portugal: Instituto Piaget, 2005.

VAN DIJK, T. A. Discurso e poder. In: HOFFNAGEL, J.; FALCONE, K. (Orgs.). São Paulo: Contexto, 2008.

VIAN JR., O. O Sistema de Avaliatividade e a linguagem da avaliação. In: VIAN JR., O.; SOUZA, A. A. de; ALMEIDA, F. A. S. D. P. (Orgs.). A linguagem da avaliação em língua portuguesa. Estudos sistêmico-funcionais com base no Sistema de Avaliatividade. São Carlos: Pedro \& João Editores, 2010. p. 19-29.

YOUNG, I. M. Representação política, identidade e minorias. Tradução de Alexandre Morales. Lua Nova, São Paulo, v. 67, p. 139-190, 2006. 